\title{
Population Fluctuation of the Peach Fruit Fly, Bactrocera zonata (Saunders) and the Mediterranean Fruit Fly Ceratitis capitata (Wiedemann) (Diptera, Tephritidae) on three Grape Varieties in Nubaria, Egypt. Seham M. Elmahdy and Y. E. Afia \\ Plant Protection Institute, A.R.C., Dokki , Giza, 12618 Egypt
}

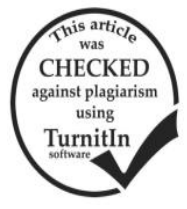

\section{ABSTRACT}

The population fluctuation of the peach fruit fly (PFF), Bactrocera zonata and the Mediterranean fruit fly (MFF), Ceratitis capitata on different grape varieties (White grape variety (Sbaror), Red grape variety (Filam) and Black grape variety (Autumn royal) were studied throughout three successive seasons 2014-2016, starting from March to September and represented by catch/trap/ daily of males on three different varieties at Nubaria district. Results revealed that the population density was the most abundant during the third season in the Sbaror, Filam and autumn royal varieties. During the three seasons, the population density of MFF was more than of PFF in all varieties. Each of B. zonata and C. capitata have one peak on Sbaror and Filam and Autumn royal varieties through period from May to July. Seasonal activity of fruit flies represented by total monthly catch of males on three varieties of grape during three successive seasons recorded the highest peak of seasonal abundance on May during the third season with total monthly catch 1050.8 males/month representing 59.2\%, while the total monthly catch of males during the two seasons were more in June were 160.46 and367.3 males/month representing 42.64 and 55\% from total population, respectively. Results obtained of seasonal fluctuation of $B$. zonata and C.capitata on three varieties grapes represented by total numbers and percentages between varieties were more on Sbaror and Filam than autumn royal where the total population for variety through three seasons $2050.38,547.84$ and 214.79 males, were recorded, respectively. The results showed that the percentage of $C$. capitata was high in the third season than second and first seasons, on the other hand the percentage of $B$. zonata was more in the first season than second and third season in all varieties. The highest total numbers of males on' Sbaror variety was $1335.9,467.8$ and 249.67 males /seasons representing $98.73,87.96$ and $79.80 \%$ for C.C and $1.27,12.04$ and $20.20 \%$ for B. zonata of total captured males, during the third, second and first seasons, respectively, while the lowest total number on Autumn royal variety was $(96.4,69.4 \& 48.99$ males/season) representing $(92.12,75.65 \& 68.09 \%)$ and $(7.88$, $24.35 \& 31.91 \%$ ) for C.C and B.Z during third, second and first seasons, respectively. Statistical analysis of variance in $2014-2016$ season showed that combined effect of the weather factors to CTD revealed EV were positively significant, in Sbaror variety, the simple correlation between maximum and minimum temperatures and CTD number were high significant and significant and the percentage of explained variance (E.V \%) were high significant and significant were 46.02 and $26.78 \%$ for during first year and second year for $B$. zonata. While the simple correlation between and relative humanity and CTD were positive significant for C. capitata during the third years. During 2015, the simple correlation between maximum temperatures and CTD number in Filam variety was significant during second year and the percentage of explained variance (E.V.\%) were significant its 26.77 and $28.14 \%$ for B. zonata and C. capitata, respectively. In Autumn royal variety, the simple correlation between maximum and minimum temperatures and CTD number were significant and high significant during first season and the percentage of explained variance (E.V.\%) were $26.75 \%$ for $B$. zonata, respectively.

\section{INTRODUCTION}

Grapevine (Vitis vinifera L., Vitaceae ) is a very important crop in the Mediterranean region. More than $40 \%$ of the world grapevine production is produced in Mediterranean countries with Italy, France and Spain being the main producers (Roditakis et al. (2008). Grape, Vitis spp. is one of the oldest types of fruit known to be cultivated in Egypt. The production of grapes in Egypt was a major affair of the Roman state. The grapes are the desired and gracious fruit of different layers. Most of crop is consumed fresh. A portion of the seedless varieties is used for drying and raisin processing, while some are directed to manufacture fresh and fermented juice. Grapes and its products have export potential. The nutritional value of its fruits is due to its easy-to-absorb glucose content as well as its biochemical components of processed minerals. The area cultivated by grapes is about $20 \%$ of the total cultivated area. The total area of grapes in Egypt reached 192873 thousand feddans according to the 2013 census and the productive area of which is 164310 thousand feddans producing 8.73 million tons with an average of (1435) tons per feddan. These areas are mainly concentrated in the governorates of Ghrapya, Mania, Nubaria, Manofaya, and there are areas in the newly reclaimed lands in, Matrouh and North Sinai. Family Tephritidae, the true fruit flies, includes about 4000 species arranged in 500 genera. As such, it is the largest families of Diptera and one of the most economically important. Including many commercial fruits. Female flies lay their eggs in the fruits and hatching maggots devour into pulp. Subsequently, secondary infestation with bacterial and fungus diseases frequent and infested fruits drop down (White \&Elson-Harries, 1994 and Abdel-Sabour, 2003). Fruit fly is one of the key pests in the production of table grapes in the Western Cape. Two species of fruit fly are involved, viz. Mediterranean fruit fly [Ceratitis capitate (Wied).] and Natal fruit fly [Ceratitis rosa (Karsch)]. Different species of Family Tephritidae have been accidentally introduced into Egypt. The Mediterranean fruit fly or Medfly, Ceratitis capitata (Wiedemann), is one of the most tephritids that infesting more than 350 host plants throughout the world (Liquido et al., 1991). while (Swart et al.,1976; Autter.1977; Castro 1982;; Elhanan \&Roessler,1992; Dhouibi\&Fellah 1997; Buonocore et al.,1999) fond that Mediterranean fruit fly has been reported as a pest or potential pest of grapevines in South Africa, Brazil, Chile , Venezula , California , Isreal , Tunisina and Italy and various control strategies have been suggested In Egypt , C. capitata attacks several host fruits which are available all over the year causing considerable damage which inflicts significantly economic losses to guava, peach, apricot, apple,fig and citrus allover the governorates of in Egypt (Saafan, 1986). During 1990 of the last century, a new fruit pest is the peach fruit fly, Bactrocera zonata (Saunder) (Diptera: Tephritidae) attack wide range of fruit species in Egypt, including mango, guava, peach, apricot, apple, citrus as well as some vegetable crops (El-Minshawy et al., 1999 and Hashem et 
al. 2001). This species has become widely spread in the country as well as $C$. capitata. This new pest attracted the attentions of many authors in Egypt, i.e. Afia (2007) and Amin (2008).

The aim of this work is to study population density of Ceratitis capitata and Bactorcera zonata on three different grape varieties under field conditions in Nubaria district.

\section{MATERIALS AND METHODS}

Seasonal abundance of the peach fruit fly $B$. zonata and Med fruit fly $C$. capitata, as well as relationship between the population activity and the prevailing climatic factors in addition to total monthly were studied for three successive seasons (2014, 2015 and 2016). Abundance was based on trap catches in three grape varieties cultivated in the same orchards' 10 feddans for each Sbaror ,Filam and Autumn royal varieties at Nubaria district. The trees of those different varieties were about 10-15 years old. Jackson traps as thirty units 15 traps baited with $4 \mathrm{ml}$ mixture of methyl eugenol (male sex attractant) $90 \%+$ sumithion $50 \%$ (Fenitrothion insectiside) at a ratio of 8:2 for monitoring of PFF and 15 traps baited with $4 \mathrm{ml}$ of Trimedlure (male sex attractant) 90\%+ dichlorophose 10\% (DDVP) (as insecticide) $10 \%$ for monitoring of MFF were distributed randomly in a grape orchards cultivated with three different varieties. Five trap as replicates were used for each variety for 18 weeks, Sbaror variety on the first week of April till last week of July, Filam variety on the last week of March till third week of July and Autumn royal variety on the first week of May till first week of September. Traps were hung at a shaded side of the tree at about 1.5-2 meters height and injected with the above mixture every 4-6 weeks during summer seasons. Traps were inspected weekly and trap catches were transferred to be captured per trap per day (CTD) in the different grape varieties from last March to first September.

\section{Statistical analysis:}

To estimate relationship between population of C. capitata and B. zonata and prevailing climatic factors, day-maximum temperature (D. Max. T.), day minimum temperature (D. Min. T.) and daily mean relative humidity (D.M. R.H.) were obtained from the Central Laboratory for Agriculture Meteorology, Agriculture Research Center. The daily records of each weather factor were calculated as weekly means representing to sampling date. Weather factors were considered over 18 weeks for each crop (i.e, Sbaror, Filam and Autumn royal ) which included the ripping stage for each crop. This was included in the multiple regression analysis. The results obtained of the mean numbers of Peach fruit fly and Med fruit fly were statistically analysed by using ANOVA. Mean separation was conducted using L.S.D. in SAS program (SAS Institute, 1988).

\section{RESULTS AND DISCUSSION}

The seasonal abundance of both fruit fly species was studied for three successive seasons (2014, 2015 and 2016 ) starting from last March to first September on three different varieties of grapes Sbaror, Filam and Autumn royal in Nubaria distrit.

\section{First season 2014:}

Results illustrated in Fig. (1) showed that the population density of PFF was lower than that of MFF in Sbaror, Filam and Autumn royal varieties. It started in low numbers on Sbaror variety (2.1 and 1.2 catch / trap/daily for the $C$. capitata and $B$. zonata, respectively) that recorded at the $15^{\text {nd }}$ April and $1^{\text {st }}$ April. These low numbers were coinciding with the beginning of the ripping period and emigration of flies previous host such as Valencia orange which was harvested earlier. The population of both species increased gradually to maked one peak on the $17^{\text {th }}$ of June and $8^{\text {th }}$ of July with mean numbers of CTD of 34.61 and7.92 flies for $C$. capitata and B. zonata. the increment may be due to the favourable weather conditions specially means of maximum, minimum temperature which were $\left(31.98\right.$ and $\left.19.85^{\circ} \mathrm{C}\right)$ and $\left(30.25\right.$ and $\left.20.99^{\circ} \mathrm{C}\right)$, respectively, as well as relative humidity of 75.71 and $71.92 \%$. This period coinciding with the fruit full ripping stage of Sbaror variety. The population density of flies was gradually decreased with the end of Sbaror harvest.

Results obtained in Figure (1) revealed that the seasonal fluctuation of $C$. capitata and $B$. zonata followed the same trend on Filam variety, the population density began with few numbers. Afterwards, population density gradually increased to record only one peak of seasonal abundance on the $27^{\text {th }}$ of May and $17^{\text {th }}$ of June, which represented by CTD of 10.23 and 4.37 flies for C. capitata and B. zonata where the maximum and minimum temperature means were $\left(29.68^{\circ} \mathrm{C}\right.$ and $\left.16.89^{\circ} \mathrm{C}\right)$ and $\left(31.98\right.$ and $\left.19.87^{\circ} \mathrm{C}\right)$, respectively, and relative humidity was 70.57 and $75.71 \%$. This period was coinciding with improvement of weather factors as well as full ripping stage of Filam. The population began to decrease gradually till late June with the end of Filam variety harvesting.

In Autumn royal variety (Fig., 1) the population density began to appear with relatively low numbers of CTD values of 0.142 and 0.243 flies for C. capitata and B. zonata on the $6^{\text {th }}$ of May and $10^{\text {th }}$ of June. Then the population for the two species increased gradually forming one peak on the $15^{\text {th }}$ and $27^{\text {th }}$ of June with CTD values of 7.83 and 4.4 flies at maximum and minimum temperature of $33.18,32.36$ and $20.97,22.33^{\circ} \mathrm{C}$ and relative humidity of 74.45 and $72.62 \%$, respectively. This period was coinciding with improvement of weather conditions as well as full ripping stage of autumn royal variety. Then the population density gradually decreased with end of autumn royal variety harvesting.

Second season (2015):

Data illustrated in Fig. (2) revealed that the population of $C$. capitata and $B$. zonata were more active than that of the first season indicating that the population density of PFF was lower than that recorded for MFF in Sbaror than Filam and Autumn royal varieties. The high population density of flies were 
Sbaror variety, it started with relativity low CTD of 1.8 and 0.402 flies for C. capitata and B. zonata on the $7^{\text {th }}$ of April, 2015. These low numbers in this locality were coinciding with lowest persistence of MFF and PFF population resulting from immigrated flies from intercropped hosts. Then the mean population density of both $C$. capitata and $B$. zonata increased gradually throughout successive inspections and recorded only one peak of seasonal abundance, represented by CTD of 78.8 and 9.8 flies on the $9^{\text {th }}$ and $23^{\text {th }}$ of June, successively. This increase may be due to the improvement of weather conditions, especially the maximum and minimum temperature which recorded $34.87,32.63^{\circ} \mathrm{C}$ and $20.3,22.7^{\circ} \mathrm{C}$, respectively, and the relative humidity of 74.57 and $78 \%$, as well as Sbaror variety fruits became in full ripping stage. Data in Fig. (2) showed that the lowest population fluctuations of both fruit flies on Autumn royal variety and the population density was nearly different than that observed in 2014 season, that began with CTD values of 0.23 and 0.5 on the $5^{\text {st }}$ of May and $23^{\text {th }}$ of June, then a gradual increase was observed during July making one peak for each species on the $7^{\text {st }}$ and $14^{\text {nd }}$ July with CTD values of 10.8 and 3.8 flies for $C$. capitata and B. zonata at maximum and minimum temperature of $33.46,30.71$ and $22,22.6^{\circ} \mathrm{C}$ and relative humidity of 74.71 and $79.29 \%$, respectively. Then the population gradually decreased with end of Autumn royal variety harvesting.
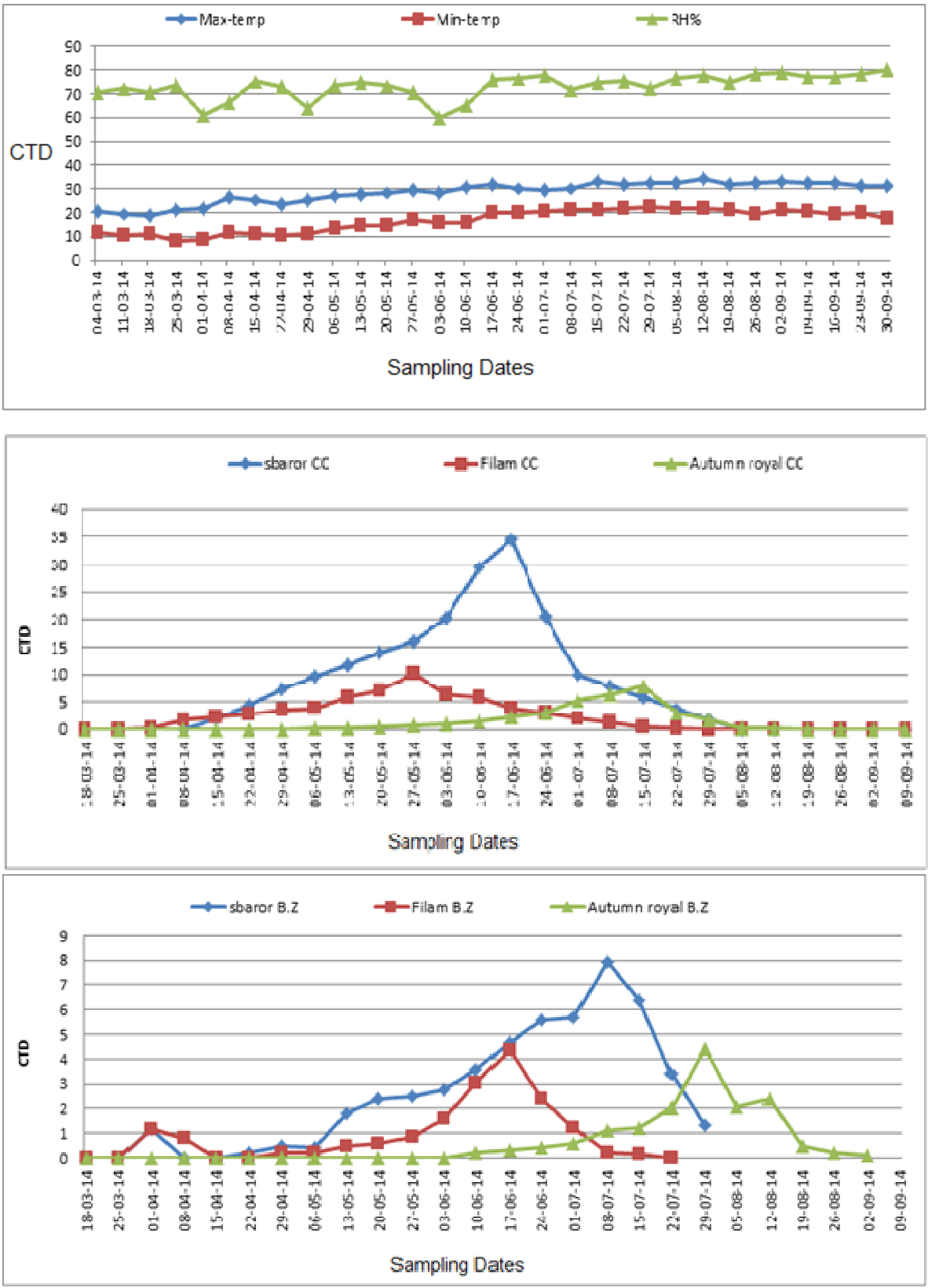

Fig. 1. CTD of attracted males of $C$. Capitata and $B$. Zonata on different grape varieties with corresponding means of main weather factors in Nubaria district during 2014 season. 

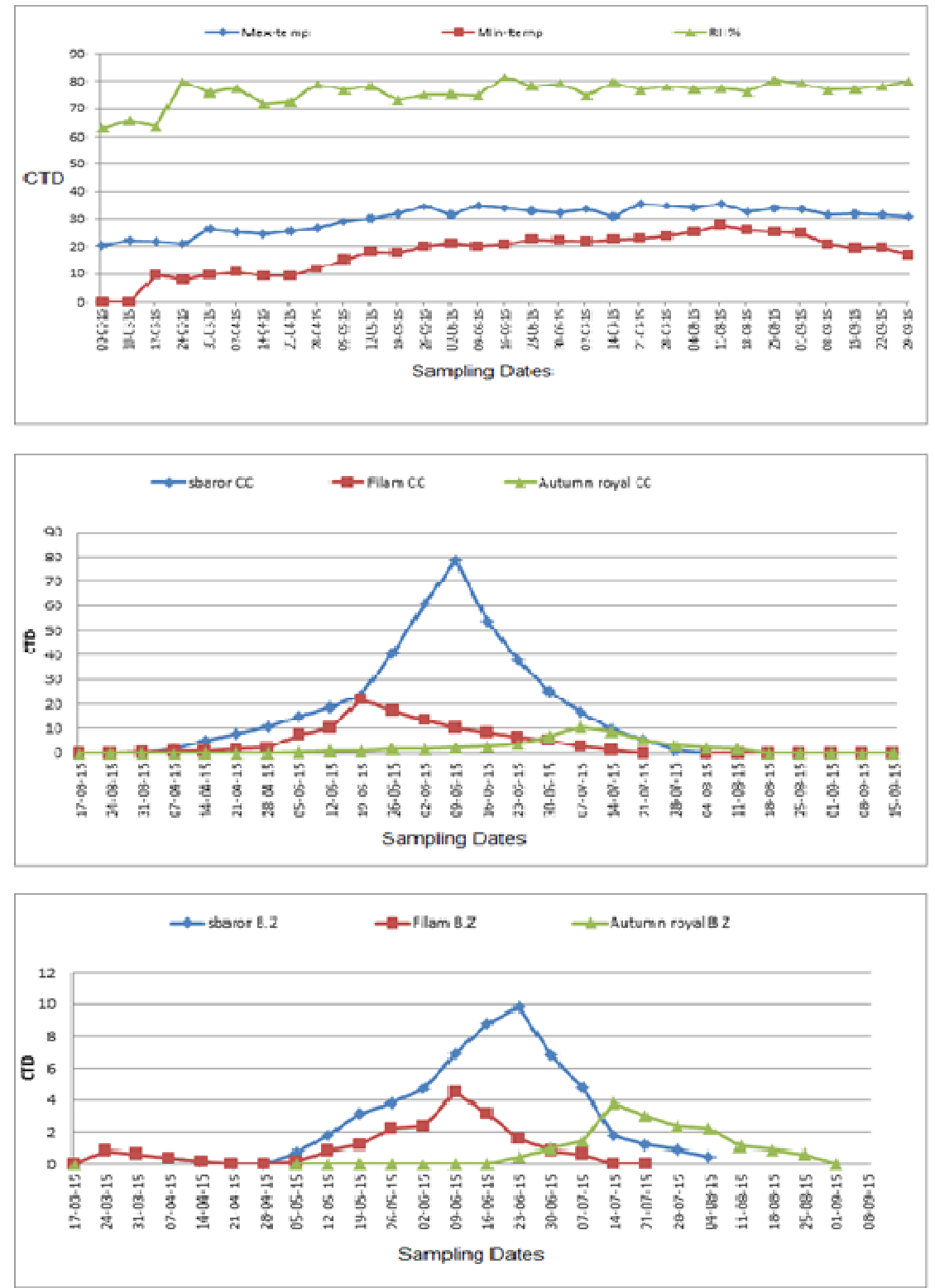

Fig. 2. CTD of attracted males of $C$. Capitata and $B$. Zonata on different grape varieties with corresponding means of main weather factors in Nubaria district, during 2015 season.

\section{Third season (2016):}

Results illustrated in Fig. (3) indicate that the most active population of $C$. capitata and B. zonata was in the third season showing that the population density of MFF was more than that of PFF in the three grape varieties. Concerning the population fluctuation of both flies on Sbaror variety trees, it started with a few numbers of 9.8 and 0.2 flies for $C$. capitata and B. zonata on the $5^{\text {st }}$ of April followed by a marked increasing to reach CTD values of 257.55 and 3.2 flies on the $31^{\text {th }}$ of May and $14^{\text {th }}$ of June for $C$. capitata and B. zonata where maximum and minimum were $33.29,31$ and $19.9,24.4^{\circ} \mathrm{C}$ and relative humidity of 52.6 and $69.35 \%$, respectively. This period was coinciding with improvement of weather factors as well as the full ripping stage of fruits. Then the population density decreased gradually with end of Sbaror variety harvesting. On the other hand, in Filam variety, the first incidence occurred on $23^{\text {th }}$ of March with relatively low values of flies which probably due to emigration flies from early intercropped hosts such as another fruits. Then, the population gradually increased to make one peak that recorded on the $17 \& 24^{\text {th }}$ of May with CTD of 72.8 and 3.8 flies for $C$. capitata and B. zonata at maximum and minimum temperature of $33.29 \& 34.57$ and $23.7 \& 20^{\circ} \mathrm{C}$, respectively, as well relative humidity of 67.4 and $53.35 \%$. After that the population decreased until end harvesting.

Results in Fig. (3) Showed that the population density of MFF and PFF appeared with relatively few numbers on autumn royal trees, represented by 0.6 and 0.264 flies for C. capitata and B. zonata on the $10^{\text {th }}$ of May $\& 21^{\text {th }}$ of June. The population density increased gradually throughout the successive weeks to record one peak of seasonal abundance represented by CTD of 18.6 and 2.4 flies for C. capitata and B. zonata on the $28^{\text {th }}$ of June and $5^{\text {st }}$ of July at maximum and minimum temperature of 34.29 , 31.86 and 24.3 and $24.6^{\circ} \mathrm{C}$ and relative humidity of 62.2 and $70.7 \%$, respectively, as well as the full ripping stage of fruits. Then the population density gradually decreased 
with end of autumn royal variety harvesting.

These data agree with those obtained by Gupta et al. (1990) found that traps captured males of B. zonata from the $2^{\text {nd }}$ week of April until the $2^{\text {nd }}$ week of November in India, Adult fly populations recorded one peak during fruit maturation in June. Also

Agarwal and Kumar (1999) stated that the average number flies traped was 39.94 and 134.92 flies/trap / week, for B. dorsalis and B. zonata between, respectively, April and August 1997 in India. Ishtiaq et al., (1999) in India observed a peak population of B. zonata for winter crop in September, while, it was negligibly in December. Khan et al. (2002) reported the maximum numbers of adult catches of $B$. zonata in July and August in mango orchards in Multan, Pakistan. The maximum infestation was recorded on 15 September and 1 October. Mohamed (2002) studied the seasonal fluctuation of B. zonata in Sohag governorate and stated that the capture concentrated on August, September and October, while in rest of the year the files disappeared or captured in few numbers. Khan et al. (2003) stated that the second fortnight of August and first fortnight of September showed maximum population of $B$. zonata trapped by pheromones in guava orchards. Kawashita et al. (2004) reported that B. zonata were attracted by methyl eugenol from April to July in Srilanka. In addition, Khalid and Mishkatullah (2007), in Pakistan, monitored $B$. zonata infecsted the fruits with low population level from November to February then increased from March to August. The population recorded one peak in July and August, while minimum level decline was observed in October depending on the host fruit maturity and prevailing temperature.
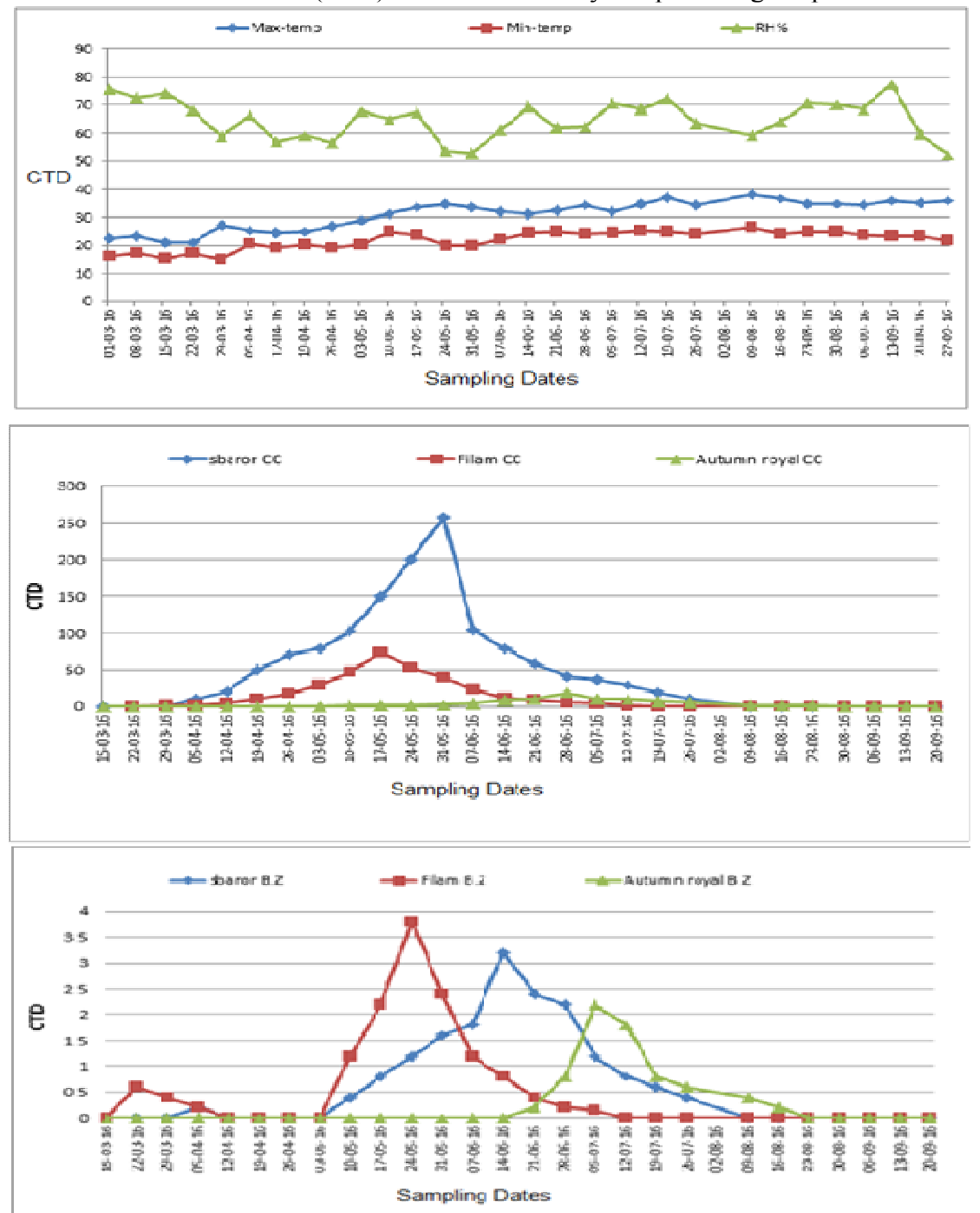

Fig. 3. CTD of attracted males of $C$. Capitata and $B$. zonata on different grape varieties with corresponding means of main weather factors in Nubaria district, during 2016 season.

Monthly seasonal activity of $\boldsymbol{B}$. zonata and $\boldsymbol{C}$. capitata population densities increase gradually in successive months on three varieties of grape:

Results obtained were given in graphically illustrated in Fig. (4), these results revealed that population density was more abundant during third season. During March of three seasons a few males were captured, this may be due to that $\mathrm{PFF}$ and MFF were overwintered during this month. The to record the make one peak of seasonal abundance on June during the $1^{\text {st }}$ and $2^{\text {nd }}$ seasons with total monthly catch of 160.46 and 367.3 males/month representing 42.64 and 55\% from total population, respectively. While the total monthly catch during the three season made the highest peak of seasonal abundance on May was 1050.8 males/ month 
representing $59.2 \%$ from total population. During this period from March to July population increased found PFF an MFF to attack Sbaror \& Failm and Autumn royal trees. These hosts were at blooming and fruiting stages. Then, population density was decreased gradually in the successive months until the end of the season.

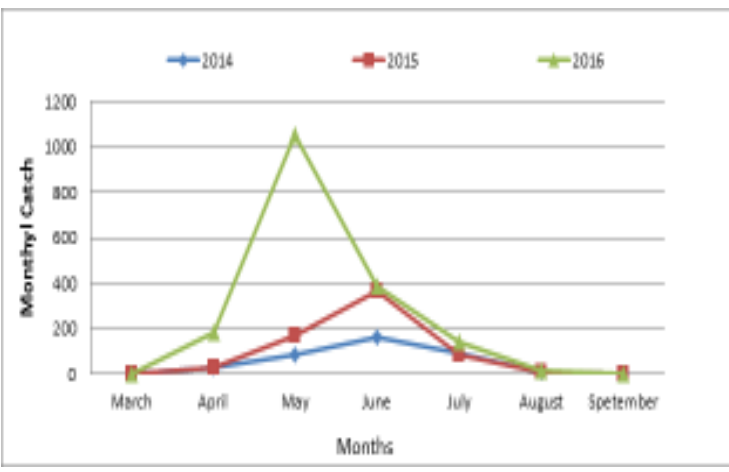

Fig. 4. Total monthly catch fly/trap of $B$. zonata and $C$. capitata on three varieties of grapes Nubaria district, Alexandria governorate during three successive seasons (2014- 2016) corresponding means of temperature and percentage of relative humidity

These results are in agreement with those obtained by Khan and Khan (1987) and Anjum et al. (2000) they found that seasonal abundance of $B$. zonata mostly occurred from March to August (especially during the July-August summer monsoon). Saafan et al. (2000) reported that throughout the period from September until November 1997 and 1998, the fallen fig fruits produced $C$. capitata and $B$. zonata only. Hashem et al. (2001) demonstrated that the peak of B. zonata in mango, apple and citrus (mandarin) orchards was in July and November/December, respectively in Egypt. Saafan (2005a, b and c) and Amin (2008) indicated that the PFF population were found significantly in higher numbers during summer and autumn seasons and diminishing during winter and spring seasons in Fayoum governorate. Afia (2007) found that the total monthly catch in Qalyubiya governorate recorded three peaks of seasonal activity. The high abundance of insect population reached the maximum level during summer season (July/ August) and the second peaks was in autumn season (September/November) while the lowest peak (third) was observed during spring season (March/May). Khalid and Mishkatullah (2007) stated that the B. zonata recorded low population level from November to February, and increased gradually from March to August. The population peak appeared in July and August, and maximum declined was observed in October depending on the host fruit maturity in Pakistan.

Results presented in Table (1) summarized these results and revealed that population density of B. zonata and $C$. capitata irrespective of varieties was more abundant during the third season than the second and first seasons were 1773.7, 666 and 376.31 males/season, respectively and the population density between varieties were more on Sbaror and Failm than autumn royal where the total population for these varieties through three season were 2050.38 ,547.8 and 214.8 males of flies, respectively. While The total numbers of males two fruit flies on' Sbaror variety was the highest as 1318.9, 411.5 and 199.24 males /seasons representing $98.73,87.96$ and $79.8 \%$ for C. capitata and $17,56.6$ and 50.44 males /seasons representing 1.27 ,12.04 and $20.2 \%$ for B. zonata of total captured males, during the third, second and first seasons, respectively. The results showed the percentage of $C$. capitata was higher during the three seasons, respectively. While the percentage of $B$. zonata was higher in the first season than that of both second and third seasons. Filam and Autumn royal varieties came in the second and third place in this order with totals of males ((328,109.3 \& 60.23 and 88.8, $52.5 \& 33.36$ males $))$ representing $(96.07,84.86 \& 77.57 \%$ and $92.12,75.65 \&$ $68.09 \%)$ for C. capitata and ((13.4, 19.5 \& 17.41 and $7.6,16.9 \& 15.63)$ representing $(3.93,15.14 \& 22.43 \%$ and $7.88,24.35 \& 31.91 \%)$ and $(64.9,47.43 \& 38.57 \%)$ and $(38.09,52.57 \& 61.43 \%)$ for B. zonata during third, second and first seasons, respectively. Statistical analysis of variance showed high significant and significant inside two fruit flies each variety of captured flies during three seasons classified according to time of maturation $(\mathrm{F}=284.00$ and 944.44), $(\mathrm{F}=233.26$ and 149.61 $) \&(\mathrm{~F}=699.25$ and 1763.8) and L.S.D. at $0.05=(1.212 \& 2.387),(32.301 \& 0.877)$ and( $1.165 \& 1.239)$ for C. capitata and B. zonata, respectively throughout all varieties

Table 1. Total numbers and population percentage captured males C.capitata and B.zonata on three varieties on grapes in Nubaria district during three season(2014-2016).

\begin{tabular}{|c|c|c|c|c|c|c|c|c|c|c|c|c|c|c|c|c|}
\hline \multirow{2}{*}{ Years } & \multirow[b]{2}{*}{$\mathrm{Cc}$} & \multirow[b]{2}{*}{$\mathbf{B z}$} & \multicolumn{3}{|c|}{ Sbaror } & \multicolumn{7}{|c|}{ Filam } & \multicolumn{3}{|c|}{ Autumn royal } & \multirow[b]{2}{*}{$\begin{array}{c}\text { Total of } \\
\text { varieties }\end{array}$} \\
\hline & & & Total & perce & tage & Ce & $\mathbf{B z}$ & Total & perce & ntage & cc & $\mathbf{B z}$ & total & percer & ntage & \\
\hline 2014 & $199.24 \mathrm{c}$ & $50.44 \mathrm{ab}$ & 249.678 & $\begin{array}{l}\text { C.C } \\
79.8\end{array}$ & $\frac{\text { B. } \mathbf{Z}}{20.2}$ & $60.23 c$ & 17.41ab & 77.64 & $\begin{array}{c}\text { C.C } \\
77.57\end{array}$ & $\frac{\text { B. } \mathbf{Z}}{22.43}$ & $33.36 \mathrm{c}$ & $15.63 a$ & 48.99 & $\begin{array}{c}\text { C.C } \\
68.09\end{array}$ & $\frac{\text { B. Z }}{31.91}$ & 376.31 \\
\hline 2015 & $411.5 b$ & $56.3 \mathrm{a}$ & 467.8 & 87.96 & 12.04 & $109.3 b$ & $19.5 \mathrm{a}$ & 128.8 & 84.86 & 15.14 & $52.5 \mathrm{~b}$ & $16.9 \mathrm{a}$ & 69.4 & 75.65 & 24.35 & 666 \\
\hline 2016 & $1318.9 \mathrm{a}$ & $17 \mathrm{c}$ & 1335.9 & 98.73 & 1.27 & $328 \mathrm{a}$ & $13.4 \mathrm{c}$ & 341.4 & 96.07 & 3.93 & $88.8 \mathrm{a}$ & $7.6 b$ & 96.4 & 92.12 & 7.88 & 1773.7 \\
\hline Total & & & 2050.38 & & & & & 547.8 & & & & & 214.8 & & & 2816 \\
\hline F value & $\begin{array}{c}* * * \\
284.00\end{array}$ & $\begin{array}{c}* \\
944.44\end{array}$ & & & & $\begin{array}{c}* * * \\
233.26\end{array}$ & ** 149.61 & & & & $\begin{array}{c}* * * \\
699.25\end{array}$ & $\begin{array}{c}* * \\
177.66\end{array}$ & & & & \\
\hline $\begin{array}{l}\text { LSD at } \\
0.05\end{array}$ & 1.2194 & 2.3874 & & & & 32.301 & 0.877 & & & & 1.1647 & 1.239 & & & & \\
\hline
\end{tabular}

These results are closely related with those obtained by Hashem et al. (2001) demonstrated that the population of B.zonata was increased gradually with fruiting and ripening, where the peak of infestation at mango and apple orchards was in July for both flies. While, on citrus (mandarin) orchard was in November/December. ElGendy (2002) stated that the host preference of peach fruit fly on six hosts depends on the total numbers of males captured by using Jackson trap could be arranged as follows: mango, mandarin, navel orange, suckary orange. Rajitha and Shashidhar (2006a) monitored that population of $B$. zonata recorded 1 and 2 peaks of seasonal abundance during the first and second seasons, respectively, in Dharwad, Karnataka, India, from July 2003 to April 2004. 
Rajitha and Shashidhar (2006b) recorded three peaks of seasonal abundance of $B$. zonata at a mango orchard in Dharwad, Karnataka, India, from July 2003 to April 2004. Afia (2007) recognized the host sequence of infestation by B. zonata in three Governorates (Fayoum, Qaluybia and Giza) during 2001/2003 according to the weekly captured of males by using Steiner traps as the flowing: mango, guava, Navel orange, mandarin, peach , apricot, balady orange, Valencia orange.

Results presented in Table (2\&3) showed that, effect the weather factors: the simple correlation between 27 factors of different temperatures, relative humanity and CTD number. 7and 2factors of 27 for Bactorcera zonata and Ceratitis capitata were positively significant, in Sabaror variety, the simple correlation between maximum and minimum temperatures and CTD number were high significant and significant were $(\mathrm{r}=0.678) \&(\mathrm{r}=-0.769)$ and $(\mathrm{r}=0.517) \&(\mathrm{r}=-0.478)$ and the percentage of explained variance (E.V \%) were high significant and significant were $46 . .02$ and $26.78 \%$ for during first year and second year for B. zonata. While the simple correlation between and relative humanity were negative significant were $(\mathrm{r}=-$ 0.567 ) for $C$. capitata during the third years. During 2015, the simple correlation between maximum temperatures and CTD number in Filam variety was significant $(r=0.517)$ and $(\mathrm{r}=0.531)$ during second year and the percentage of explained variance (E.V.\%) were significant its 26.77 and $28.14 \%$ for B. zonata and C. capitata, respectively. In Autumn royal variety, the simple correlation between maximum and minimum temperatures and CTD number were significant and high significant $(\mathrm{r}=0.517$ and $\mathrm{r}=0.659)$ during first season and the percentage of explained variance (E.V.\%) were $26.75 \%$ for B. zonata, respectively.

From the abovementioned discussion it could be stated that the changes population densities of $B$. zonata and $C$. capitata at the three grape varieties in Nubaria distrit were mostly related to the simultaneous effects of the all factors selected (three weather factors and CTD ) than the single effect of each factor separately. The percentages of explained variance were highly significant or significant and non-significant during 2014 \&2015 seasons at the three grape varieties. The remaining unexplained variance were assumed to be due to the influence of other inconsiderable factors (biological, environ-mental, blooming and fruiting stages of the hosts and ripping stage of the fruit).

Table 2. Simple correlation and regression values between the weather factors relation with capture males trap daily(CTD) of the Peach fruit fly, Bactercera Zonata on different grape varieties in Nubaria distrit during 2014-2016 season.

\begin{tabular}{|c|c|c|c|c|c|c|c|c|c|}
\hline \multirow{2}{*}{ Grape } & \multirow{2}{*}{ Year } & \multirow{2}{*}{ Variable } & \multicolumn{2}{|c|}{ Simple correlation } & \multicolumn{5}{|c|}{ Partial regression } \\
\hline & & & $\mathbf{R}$ & $\mathbf{P}$ & b & $\mathbf{P}$ & $\mathbf{F}$ & $\mathbf{P}$ & EV\% \\
\hline \multirow{9}{*}{ Sbaror } & \multirow{3}{*}{2014} & Temp. max. & 0.67841 & 0.002 & 3.69 & 0.002 & \multirow{3}{*}{13.64} & \multirow{3}{*}{0.002} & \multirow{3}{*}{46.02} \\
\hline & & Temp. min. & 0.76687 & 0.0002 & 4.78 & 0.0002 & & & \\
\hline & & RH \% & 0.3267 & 0.1858 & 1.38 & 0.1858 & & & \\
\hline & \multirow{3}{*}{2015} & Temp. max. & 0.51747 & 0.0278 & 2.42 & 0.0278 & \multirow{3}{*}{5.85} & \multirow{3}{*}{0.0278} & \multirow{3}{*}{26.78} \\
\hline & & Temp. min. & 0.47776 & 0.0449 & 2.18 & 0.0449 & & & \\
\hline & & RH \% & 0.28724 & 0.2478 & 1.2 & 0.2478 & & & \\
\hline & \multirow{3}{*}{2016} & Temp. max. & 0.4212 & 0.0817 & 1.86 & 0.0817 & \multirow{3}{*}{3.45} & \multirow{3}{*}{0.0817} & \multirow{3}{*}{17.74} \\
\hline & & Temp. min. & -0.05488 & 0.8288 & -0.22 & 0.8288 & & & \\
\hline & & RH \% & -0.43494 & 0.0713 & -1.93 & 0.0713 & & & \\
\hline \multirow{9}{*}{ Filam } & \multirow{3}{*}{2014} & Temp. max. & 0.40547 & 0.095 & 1.77 & 0.095 & \multirow{3}{*}{3.15} & \multirow{3}{*}{0.095} & \multirow{3}{*}{16.44} \\
\hline & & Temp. min. & 0.31474 & 0.2033 & 1.33 & 0.2033 & & & \\
\hline & & RH \% & -0.09815 & 0.6984 & -0.39 & 0.6984 & & & \\
\hline & \multirow{3}{*}{2015} & Temp. max. & 0.51744 & 0.0279 & 2.42 & 0.0279 & \multirow{3}{*}{5.85} & \multirow{3}{*}{0.0279} & \multirow{3}{*}{26.77} \\
\hline & & Temp. min. & 0.39657 & 0.1032 & 1.73 & 0.1032 & & & \\
\hline & & $\mathrm{RH} \%$ & 0.04549 & 0.8578 & 0.18 & 0.8578 & & & \\
\hline & \multirow{3}{*}{2016} & Temp. max. & 0.4212 & 0.0817 & 1.86 & 0.0817 & \multirow{3}{*}{3.45} & \multirow{3}{*}{0.0817} & \\
\hline & & Temp. min. & -0.05488 & 0.8288 & -0.22 & 0.8288 & & & 0.1774 \\
\hline & & RH \% & -0.43494 & 0.0713 & -1.93 & 0.0713 & & & \\
\hline & & Temp. max. & 0.51718 & 0.028 & 2.42 & 0.028 & & & \\
\hline & 2014 & Temp. min. & 0.65939 & 0.0029 & 3.51 & 0.0029 & 5.84 & 0.028 & 26.75 \\
\hline & & RH \% & 0.18058 & 0.4733 & 0.73 & 0.4733 & & & \\
\hline & & Temp. max. & 0.22182 & 0.3764 & 0.91 & 0.3764 & & & \\
\hline Autumn & 2015 & Temp. min. & 0.41622 & 0.0858 & 1.83 & 0.0858 & 0.83 & 0.3764 & 4.92 \\
\hline & & RH \% & 0.17197 & 0.495 & 0.7 & 0.495 & & & \\
\hline & & Temp. max. & 0.07283 & 0.774 & 0.29 & 0.774 & & & \\
\hline & 2016 & Temp. min. & 0.34523 & 0.1606 & 1.47 & 0.1606 & 0.09 & 0.774 & 0.53 \\
\hline & & $\mathrm{RH} \%$ & 0.33525 & 0.1738 & 1.42 & 0.1738 & & & \\
\hline
\end{tabular}

These data are in agreement with those obtained by Abu-Manzar and Srivastava (2004a) reported the population of $B$. zonata showed a significant correlation with minimum temperature during 2002. The maximum and minimum relative humidity and rain was negatively and in significantly correlated during both years, except with minimum relative humidity and rain during 2003 in cue-lure and rain during 2003 in methyl. However Afia (2007) found that the weather factors were not the main driver for the population dynamics of both fruit flies in different corps at three governorates and for sure, weather factors are main players (with other environmental and agricultural procedures) in providing appropriate stage of host for fruit flies (i.e. mature or ripening of fruit hosts) but it might not be the main controller for fruit flies population dynamics. Thus, the availability of alternate fruit host and appropriate host stage for infestation are limiting factors for pest abundance. Amin (2008) In Egypt found that the weather factors were apparent during periods of critical temperature, particularly during winter months in which population of $B$. zonata reduced to its minimal numbers. Also during summer months, the peach fruit fly was found to be adversely by such temperature increasing over optimal range $\left(30^{\circ} \mathrm{C}\right)$. Khalaf, et al., (2011) found that the 
number of pest was higher in 2010 compared to 2009, but the high temperature degree $45-51 \mathrm{C}$ in August 2010 caused decreasing the population density of Ceratitis capitata, (Wiedemann). EL-Fatih et al. (2016) in Egypt studied plant age and some weather factors on Aphis gossypii (Glover) population on four some vegetables, they found the effect weather factors are firstly affect the plant growth which makes the plant more palatable for infestation, so plant phenology as plant age took over the effect weather factors mathematically.

Table 3. Simple correlation and regression values between the weather factors relation with capture males trap daily (CTD) of the Med fruit fly, Ceratitis Capitata (Wed) on different grape varieties in Nubaria distrit during 2014-2016 season.

\begin{tabular}{|c|c|c|c|c|c|c|c|c|c|}
\hline \multirow{2}{*}{ Grape } & \multirow{2}{*}{ Year } & \multirow{2}{*}{ Variable } & \multicolumn{2}{|c|}{ Simple correlation } & \multicolumn{5}{|c|}{ Partial regression } \\
\hline & & & $\mathbf{R}$ & $\mathbf{P}$ & $\mathbf{B}$ & $\mathbf{P}$ & $\mathbf{F}$ & $\mathbf{P}$ & EV\% \\
\hline \multirow{9}{*}{ Sbaror } & \multirow{3}{*}{2014} & Temp. max. & 0.4244 & 0.0792 & 1.87 & 0.0792 & \multirow{3}{*}{3.51} & \multirow{3}{*}{0.0792} & \multirow{3}{*}{18.01} \\
\hline & & Temp. min. & 0.27629 & 0.2671 & 1.15 & 0.2671 & & & \\
\hline & & RH \% & 0.01189 & 0.9626 & 0.05 & 0.9626 & & & \\
\hline & \multirow{3}{*}{2015} & Temp. max. & 0.41111 & 0.0901 & 1.8 & 0.0901 & \multirow{3}{*}{3.25} & \multirow{3}{*}{0.0901} & \multirow{3}{*}{16.9} \\
\hline & & Temp. min. & 0.26079 & 0.2959 & 1.08 & 0.2959 & & & \\
\hline & & RH \% & 0.01456 & 0.9543 & 0.06 & 0.9543 & & & \\
\hline & & Temp. max. & 0.15324 & 0.5438 & 0.62 & 0.5438 & \multirow{3}{*}{0.38} & \multirow{3}{*}{0.5438} & \multirow{3}{*}{2.35} \\
\hline & \multirow[t]{2}{*}{2016} & Temp. min. & -0.3445 & 0.1615 & -1.47 & 0.1615 & & & \\
\hline & & $\mathrm{RH} \%$ & -0.56699 & 0.0141 & -2.75 & 0.0141 & & & \\
\hline \multirow{9}{*}{ Filam } & \multirow{3}{*}{2014} & Temp. max. & 0.21736 & 0.3863 & 0.89 & 0.3863 & \multirow{3}{*}{0.79} & \multirow{3}{*}{0.3863} & \multirow{3}{*}{4.72} \\
\hline & & Temp. min. & 0.04382 & 0.8629 & 0.18 & 0.8629 & & & \\
\hline & & RH \% & -0.16331 & 0.5173 & -0.66 & 0.5173 & & & \\
\hline & \multirow{3}{*}{2015} & Temp. max. & 0.53051 & 0.0235 & 2.5 & 0.0235 & \multirow{3}{*}{6.27} & \multirow{3}{*}{0.0235} & \multirow{3}{*}{28.14} \\
\hline & & Temp. min. & 0.35747 & 0.1453 & 1.53 & 0.1453 & & & \\
\hline & & $\mathrm{RH} \%$ & -0.23644 & 0.3449 & -0.97 & 0.3449 & & & \\
\hline & & Temp. max. & 0.35521 & 0.148 & 1.52 & 0.148 & \multirow{3}{*}{2.31} & \multirow{3}{*}{0.148} & \\
\hline & \multirow[t]{2}{*}{2016} & Temp. min. & 0.10934 & 0.6658 & 0.44 & 0.6658 & & & 12.62 \\
\hline & & RH \% & -0.22957 & 0.3595 & -0.94 & 0.3595 & & & \\
\hline & & Temp. max. & 0.08947 & 0.724 & 0.36 & 0.724 & & & \\
\hline & 2014 & Temp. min. & 0.35224 & 0.1517 & 1.51 & 0.1517 & 0.13 & 0.724 & 0.8 \\
\hline & & $\mathrm{RH} \%$ & 0.00801 & 0.9748 & 0.03 & 0.9748 & & & \\
\hline & & Temp. max. & 0.09999 & 0.693 & 0.4 & 0.693 & & & \\
\hline Autumn & 2015 & Temp. min. & 0.05827 & 0.8183 & 0.23 & 0.8183 & 0.16 & 0.693 & 1 \\
\hline & & RH \% & 0.01493 & 0.9531 & 0.06 & 0.9531 & & & \\
\hline & & Temp. max. & -0.20977 & 0.4035 & -0.86 & 0.4035 & & & \\
\hline & 2016 & Temp. min. & 0.1787 & 0.478 & 0.73 & 0.478 & 0.74 & 0.4035 & 4.4 \\
\hline & & RH \% & 0.07525 & 0.7666 & 0.3 & 0.7666 & & & \\
\hline
\end{tabular}

\section{REFERENCES}

Abdel-Sabour, M. N. (2003): Role of certain fruit flies (Diptera :Tephritidae) in the transmission of some fungal disease affecting orchards fruits. M. Sc. Thesis, Fac. Agric., Cairo. Univ. Egypt.

Abu-Manzar, S. and J.P. Srivastava (2004a). Puter program to calculate life table parameters for an insect or mite species. Florida Entomolmgist ; 69 (4): 690-697.

Afia, Y.E. (2007). Comparative studies on the biology and ecology of the two fruit flies, in Egypt, Bacterocera zonata (Saunders) and Ceratitis capitata (Wiedemann). Ph.D. Thesis, Fac. Agric. Cairo. Univ. Egypt ; 301pp.

Agarwal , M. L. and P. Kumar (1999). Effect of weather parameters on population dynamics of peach fruit fly, Bacterocera zonata (Saunders). Entomol.; 24 (1): 81-84

Amin, A.A. (2008). Ecological and biological studies on the peach and Mediterranean fruit flies in Fayoum governorate. Ph.D. Thesis, Fac. Agric. Fayoum Univ. Egypt, 255pp.

Anjum, S.; M. Razaq and M. S. Yazadni (2000). Studies on seasonal activity and control of fruit flies, Dacus spp. on mango, Mangifera indica L. at Faisalabad, Pakistan. Arab J. Plant Prot.; 18 (2): 121-123.

Autter, S.H (1977): Current fruit fly situation in Chile . FAO Plant Protection Bulletin 25, 118-119.

Buonocore , E., Colombo, A , Campe , G.\& Nucifora . A. (1999): Symptoms of damage caused by on Ceratitis capitata clusters of "Italia grapes “ Informatore Fitopatologico 49,56-60.
Castro(1982) : Medfly : what happens in calforia Informatore Fitopatologico 32,10-13.

Dhouibi, M . H. and Fellah , H. (1997): Use of host marking pheromone in the control of the fruit fly Ceratitis capitata Wied (Diptera:Tephritidae) . Bulletin-OILB/SROP . 20, 156-167.

EL-Fatih, Monira, M.; Azza, K . Emam ; M. M. Abou-Setta ; S . M. Saleh S.M.S, Darbein (2016): Influence of plant phenology (AS PLANT AGE) and some weather factors on Aphis gossypii glover population on four Solanaceae crops. Egypt. Acad . J. Biolog. Sci., (A-Entomology), 9(2):7-14.

El-Gendy, I. R. I. (2002). Studies on Peach fruit fly, Bactrocera zonata (Saund.) at El-Beheira Governorate. M. Sc. Thesis, Fac. Agric., Alexandria University. 127pp.

Elhanan , S. and Roessler ,Y. (1992): Centrally organized control of Mediterranean fruit fly Ceratitis capitata in citrus groves, orchareds and vineyards (in Israel) Hassadeh. 72,873-875.

El-Minshawy, A. M.; M. A. El-Eryan and A. I. Awad (1999): Biological and morphological studies on the guava fruit fly Bactrocera zonata (Saunders) (Diptera:Tephritidae) found recently in Egypt. $8^{\text {th }}$ Nat. Conf. Pests \& Dis of Veg. \& Fruits in Ismailia, Egypt : 71-82.

Gupta, D.; A. K . Verma and O. P. Bhalla (1990): Population of fruit flies (Dacus zonatus and D. dorsalis) infesting fruit crops in north Western Himalayan region. Indian. J. Agric. Sci., 60 (7): 471-474. 
Hashem, A. G.; M.S. A. Mohamed and M. F. El-Wakkad (2001): Diversity and abundance of Mediterranean and peach fruit flies (Diptera : Tephritidae) in different horticultural orchards. Egyptian J. Appl. Sci., 16 (2): 303-314.

Ishtiaq, A.; U. Farman and A. K. Shah (1999): Efficacy of various insecticides and trap highest in methyl eugenol baited traps against fruit flies (Bactrocera spp.). Sarhad J. Agric.; 15 (6): 589-594.

Kawashita , T .; G . B. J .P. Rajapakse and K. Tsuruta (2004): Population surveys of Bactrocera fruit flies by lure trap in Sri Lanka. Research Bulletin of the Plant Protection Service Japan, 40 (8): 83-87.

Khalaf, M.Z. , Hassan, B.H, Shbar, A.K, Naher, F.H, Salman,A.H, Jabo,N.F. (2011) : Current status of population Density of Mediterranean Fruit fly (Ceratitis capitata) in Fruit orchards in Central Iraq. Jo,311urnal of Agricultural Science and Technology A :773-777.

Khalid, M. and Mishkatullah, S. (2007): Population dynamics of three species of genus Bactrocera (Diptera: Tephritidae: Dacinae) in BARI, Chakwal. Punjab Pakistan Journal of Zoology, 39(2): 123-126.

Khan, M. A.; A. Muhammad and K. Abdul (2003): Population of fruit fly species trapped by methyl euginol and cue lure versus infestation in guava orchards. Pakistan Entomologist, 25 (1): 63-67.

Khan, M. A.; A. Muhammad; K. Abdul and A. Amjad (2002): Effect of pheromone traps on the population capture of fruit fly species and their infestation in mango orchards at Multan. Pakistan Entomologist; 24 (2): 153-157.

Khan, R. J. and M. A. J. Khan (1987): A comparative morphological study on third instar larvae of some Dacus species (Tephritidae: Diptera) in Pakistan. Pakistan J. of Scientific and Industrial Research, 30: 534-538

Liquido ,N.J. ;Shinoda , L.A. and. Cunningham, R.T.(1991): Host plants of the Mediterranean fruit fly Ceratitis capitata (Wied.) Monograph of the Etomol. Soc .Am. Publication No.77.

Mohamed, A. M. (2002): Seasonal abundance of the peach fruit fly, Bactrocera zonata (Saunders) with relation to prevailing weather factors in Upper Egypt. Assuit J. Agric. Sci.; 33 (2), 195-207.
Rajitha, A. R. and V. Shashidhar (2006a) : Monitoring of fruit flies (Diptera: Tephritidae) in guava orchard at Dharwad , Karnataka Journal of Agricultural Sciences ; 19(1): 45-49

Rajitha, A. R. and V. Shashidhar (2006b): Investigations on the population dynamics of fruit flies in mango orchard at Dharwad. Karnataka. Ibid; 19(1): 134137.

Roditakis, E., Tsagkarakou A. and Roditakis N.E. (2008): Extensive damage on white variety table grapes by the Mediterranean fruit fly Ceratitis capitata (Wiedemann) in Crete. OEPPLEPPO Bulletin, 38: 216-219.

Saafan, M.H. (2005a): Field evaluation of some attractants for attracting the adults of Mediterranean fruit fly, Ceratitis capitata and peach fruit fly, Bactrocera zonata (Saunders), in mango orchards. Ibid; 83(3): 1107- 1119

Saafan, M. H. (1986): Studies on the Mediterranean fruit fly Ceratitis capitata Wied. With emphasis on sterile male techinques (SIT) .Ph. D. Thesis, Fac., Cairo Univ .Egypt.88pp

Saafan, M. H. (2000): Field evaluation of some attractants for attracting the adults of Mediterranean fruit fly Ceratitis capitata (Wied.) Egypt. J. Agric. Res., 78 (1): 97-107.

Saafan, M. H. (2005b). Field evaluation of some attractants for attracting the adults of Mediterranean fruit fly, Ceratitis capitata (Wiedemann), and peach fruit fly, Bactrocera zonata (Saunders), in citrus orchards. Ibid; 83(3):1141-1156.

Saafan, M. H. (2005c). Field evaluation of some attractants for attracting adults of fruit flies. Ibid; 83(4): 1625 1634.

SAS Institute (1988): SAS/STAT User`s Guide, Ver. 6.03. SAS Institute Inc., Cary, North Carolina.

Swart, P.L., Branes, B.N. and Myburgh ,A.C. (1976):Pests of table grapes in the Western Cape . Deciduous Fruit Grower.26, 169-172.

White, I. M. and M. M. Elson- Harris (1994): Fruit flies of economic significant; their identification and bionomics. Wallingford, UK :CAB International and Aciar , 601pp.

\footnotetext{
تذبذب التعاد لذباب ثُمارالفاكهة علي أصناف العنب المختلفة في منطقة النويارية

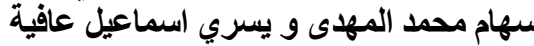
معه بحوث وقاية النباتات ـ مركز البحوث الزراعية ـ الدقي ـ الجيزة - 21618 مصر

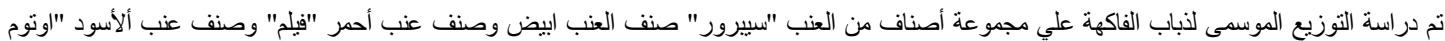

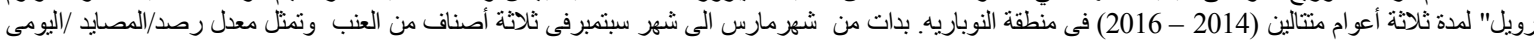

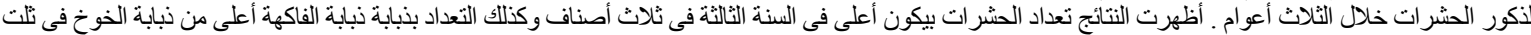

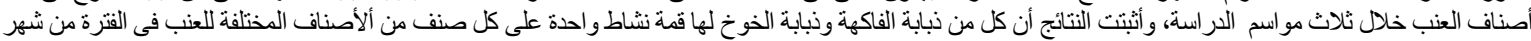

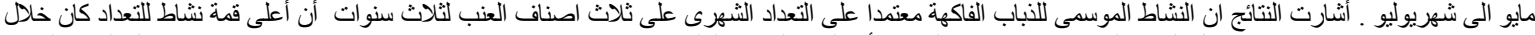

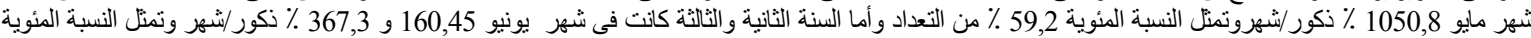

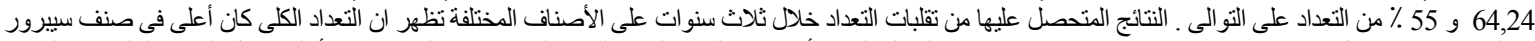

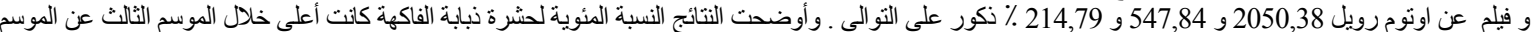

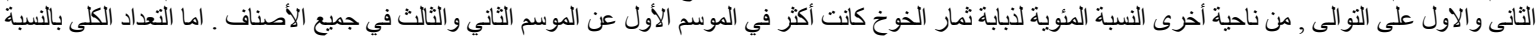

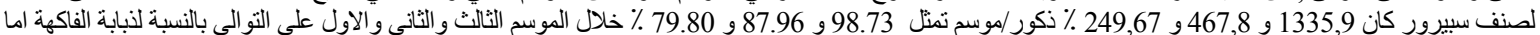

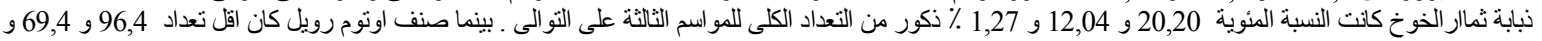

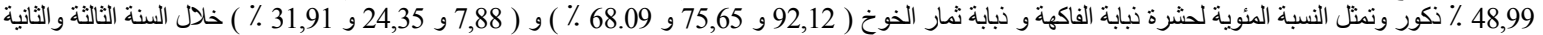

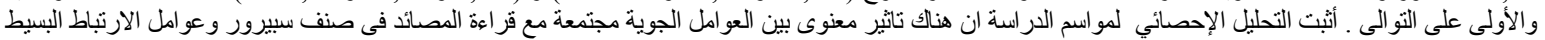

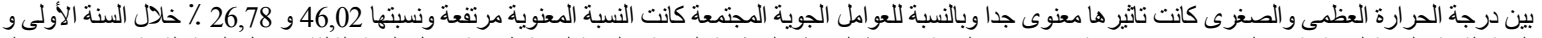

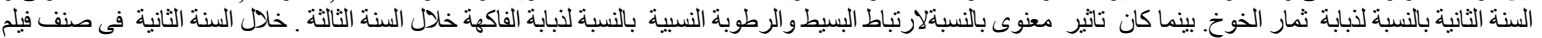

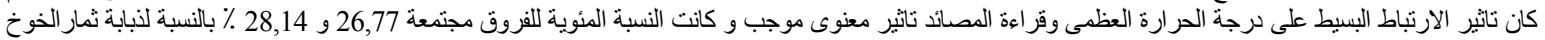

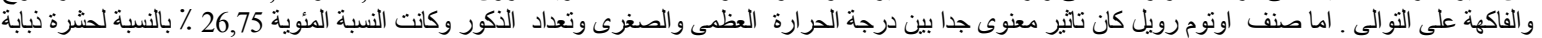
ثمار الخوخ خلال اللنة الأولى .
} 